\title{
Involvement of death receptor Fas in germ cell degeneration in gonads of Kit-deficient $W^{v} / W^{v}$ mutant mice
}

\author{
S Sakata ${ }^{1}, K_{\text {K Sakamaki }}{ }^{1}$, K Watanabe $^{1}$, N Nakamura ${ }^{2}$, \\ S Toyokuni ${ }^{3}$, Y Nishimune ${ }^{4}, C$ Mori $^{5}$ and S Yonehara ${ }^{*, 1}$ \\ ${ }^{1}$ Graduate School of Biostudies and Institute for Virus Research, Kyoto \\ University, Shogoin-Kawahara-cho, Sakyo-ku, Kyoto 606-8507, Japan \\ 2 Graduate School of Medicine, Nagoya University, Showa-ku, Nagoya 466- \\ 8550, Japan \\ ${ }^{3}$ Graduate School of Medicine, Kyoto University, Sakyo-ku, Kyoto 606-8501, \\ Japan \\ 4 Institute for Microbial Diseases, Osaka University, Suita 536-0871, Japan \\ ${ }^{5}$ Graduate School of Medicine, Chiba University, Chuoh-ku, Chiba 260-8670, \\ Japan \\ * Corresponding author: S Yonehara, Graduate School of Biostudies and \\ Institute for Virus Research, Kyoto University, Shogoin-Kawahara-cho, Sakyo- \\ ku, Kyoto 606-8507, Japan. Tel: 8175751 4783; Fax: 8175751 4784; E-mail: \\ syonehar@virus.kyoto-u.ac.jp
}

Received 8.11.02; accepted 30.12.02

Edited by $\mathrm{H}$ Ichijo

\begin{abstract}
Kit and its ligand stem cell factor (SCF) play a fundamental role in hematopoiesis, melanogenesis and gametogenesis. Homozygous $W^{v}$ mutant mice with a mutation in kit show abnormalities in these cell lineages. Fas is a member of the death receptor family inducing apoptosis. In this study, we generated double-mutant mice $\left(W^{V} / W^{v}: F^{-l-}\right)$ and analyzed histologically their reproductive organs. In testes and ovaries of the double-mutant mice, testicular germ cells and oocytes were detected, respectively, whereas the same-aged $W^{W} / W^{N}$ mice contained neither cells. In addition, inhibition of Kit signals by administration of anti-Kit mAb, which induces degeneration of testicular germ cells in vivo in wild-type mice, did not cause degeneration in Fas-deficient mice. In testicular germ cells of $W^{N} / W^{v}$ mutant mice, an increase of Fas expression was observed in spermatogonia. Further, in vitro treatment with SCF was shown to downregulate Fas on fibroblasts expressing exogenous Kit through activation of PI3-kinase/Akt. All the results clearly indicate that Fasmediated apoptosis is involved in germ cell degeneration accompanied by defects in Kit-mediated signals, and Kit signaling negatively regulates Fas-mediated apoptosis in vivo.

Cell Death and Differentiation (2003) 10, 676-686. doi:10.1038/ sj.cdd. 4401215
\end{abstract}

Keywords: Fas; germ cell; kit receptor; stem cell factor; $W^{\nu}$ mutant mouse

\begin{abstract}
Abbreviations: ERK, extracellular signal-regulated kinase; MEK, MAP kinase-ERK kinase; PI3K, phosphatidylinositol 3phosphate kinase; RTK, receptor tyrosine kinase; SCF, stem cell factor.
\end{abstract}

\section{Introduction}

Kit is a receptor tyrosine kinase (RTK) belonging to the PDGF receptor/CSF-1 receptor family. ${ }^{1-3}$ Kit and its ligand, stem cell factor (SCF), play a fundamental role during the establishment and maintenance of the three stem cell populations: melanoblasts, hematopoietic stem cells and germ cells. Genes encoding Kit and SCF are mapped to the white spotting $(W)$ and steel $(S I)$ loci in mice, respectively. ${ }^{4-8}$ Both mutant mice of $W$ and $S /$ loci show similar phenotypes such as severe macrocytic anemia, a decreased number of mast cells, a complete lack of coat pigmentation and infertility. ${ }^{9}$ Further, many alleles of variable severity at both $W$ and $S I$ loci have been identified. ${ }^{10}$ For example, $W^{N}$ mutant mice with the C57BL/6 background have a point mutation in the cytoplasmic region of Kit, resulting in no coat pigmentation, severe anemia, a deficiency of mast cells and infertility in homozygotes $\left(W^{N} / W\right) .^{11,12}$

In reproductive organs, Kit plays essential roles in spermatogenesis and oogenesis. ${ }^{10}$ In the testes, Kit receptor expression is restricted to differentiating type A to type B spermatogonia, primary spermatocytes and Leydig cells. ${ }^{13-16}$ In particular, type A spermatogonia cells express a maximal amount of Kit at both the transcript and protein level, followed by type B spermatogonia. ${ }^{13,17,18}$ Therefore, the germ cells of the homozygous $W$ mutant mice are impossible to develop and degenerate accompanied by apoptosis leading to infertility owing to a lack of Kit signals. ${ }^{18}$ In the ovaries, Kit is expressed on not only primordial and growing oocytes throughout the development of follicles but also on interstitial theca cells. ${ }^{13,18}$ In the ovaries of $W$ mice, oogenesis completely fails because of defects of Kit signals resulting in no follicles and oocytes. ${ }^{10}$

Members of the RTK family play essential roles in the proliferation, differentiation, migration and survival of various cells. ${ }^{19}$ Kit as well as other RTKs interacts with several intracellular signal transducers including PI3-kinase, JAK2, STAT1, src-related kinases, SH2-containing tyrosine phosphatases and adaptor proteins such as SOCS1, Shc, GRB2 and GRB7. These signal transducers function in various cellular processes by activating target molecules including PKC, Akt and MAP kinases such as ERK and JNK. ${ }^{20}$ Kit is strongly suggested to be indispensable for not only a mitogenic response but also an antiapoptotic response.

Fas is a cell surface receptor belonging to the death receptor family, along with tumor necrosis factor receptor 
type1 (TNF-R1) and TRAIL receptors. ${ }^{21}$ Fas can induce cell death in a variety of tumors and lymphocytes by ligation with Fas ligand or an agonistic anti-Fas monoclonal antibody (mAb). ${ }^{22-25}$ While the physiological role of Fas has been well studied in the immune system, ${ }^{26-29}$ Fas mRNA is expressed at high levels in not only the thymus and spleen, but also the liver, heart, lungs and ovaries of mice. ${ }^{26,30}$ Therefore, it could be that Fas acts in the physiological deletion of potentially harmful or unnecessary cells in these tissues. ${ }^{28}$

In female gonads, we and others demonstrated that Fas is expressed on granulosa cells of various follicles and luteal cells. ${ }^{31-38}$ A few reports showed Fas expression on oocytes, but we have not been able to confirm this. ${ }^{32,38,39}$ The expression on granulosa and luteal cells suggests that Fas is involved in follicular atresia and luteolysis for the gonadal homeostasis of adult mice. In male gonads, Fas and Fas ligand are detected in the testes, but their function is still unclear. As Fas-deficient mice showed no abnormality in the testes, ${ }^{40}$ it was thought that Fas is not essential in germ cell homeostasis. However, recent reports insisted on the involvement of Fas in the physiological death of germ cells. ${ }^{41-43}$ In addition, Fas expression was shown to increase in the testes after drug treatment, ischemia-reperfusion or heat shock. ${ }^{44-47}$ In these damaged testes, Fas may play a role as a regulator of pathological germ cell death, although this has not been clearly determined.

To investigate the relation between Kit-mediated survival signals and Fas-mediated apoptotic signals in gonads, we generated double-mutant mice by intercrossing Kit-deficient $W^{N}$ mutant mice with Fas knockout mice. Our study clearly demonstrated that a defect of Kit signaling leads to activation of a Fas-mediated apoptotic signal in both spermatogenesis and oogenesis, and Fas is involved in germ cell loss in Kit signaling-deficient mice. Moreover, our findings provide new evidence of crosstalk of signals via Kit and Fas, indicating that Kit-induced signals negatively regulate Fas expression in the gonads.

\section{Results}

\section{Analysis of double-mutant mice}

In the gonads of Kit-deficient $W$ mutant mice, the degeneration of testicular germ cells and oocytes was reported to be accompanied by cell death. ${ }^{10}$ We investigated whether Fas is involved in these events because we and other groups previously showed the expression of Fas in both male and female gonads. ${ }^{31-38,41,43-46}$ To clarify whether Fas is involved in germ cell degeneration in the gonads of $W$ mutant mice, we generated double-mutant mice $\left(W^{N} W^{N}: \mathrm{Fas}^{-1-}\right)$ by intercrossing the spontaneous Kit mutant $W^{N}$ mice with Fas-deficient mice against the same C57BL/6 background.

We first examined whether the number of germ cells in the gonads of the mutant mice changes with the Fas gene status. The number of $W^{N} / W^{N}$ homozygous newborns was less than that expected as a result of Mendel's laws, while a significant effect of Fas gene status was not observed. In addition, $W^{N} /$ $W^{N}$ homozygous mice often died within 2 weeks because of anemia (data not shown), while some mutant mice survived for more than 8 weeks. Their testes and ovaries could then be examined. We measured the size of the testes of the surviving $W^{N}$ mutant mice, and found the testes of $W^{N} / W^{N}$ homozygous mice to be smaller (approximately 10-20\% in size) than those of $W^{N} /+$ or wild-type mice regardless of Fas status (data not shown).

\section{Histological analysis of testes in the double- mutant mice}

Next, we histologically examined the testes of the 8-week-old mutant mice by staining with hematoxylin and eosin (Figure 1). Testes of $W^{N} /+$ Fas $^{-1-}$ mice were histologically normal. Germ cells at all developmental stages including spermatogonia, primary spermatocytes, secondary spermatocytes, haploid spermatids and sperm were observed (Figure 1a,d). Fasdeficiency did not induce hyperplasia of germ cells in these mutant male mice. In the testes of $W^{N} / W^{N}: \mathrm{Fas}^{+/+}$mice, seminiferous tubules were abnormal, resulting in no differentiated germ cells (Figure 1b,e), as described previously in $W^{N}$ mutant mice. ${ }^{10}$ Interestingly, in the testes of $W^{N} / W^{V}:$ Fas $^{-1-}$ mice, spermatocytes, spermatids and sperm were detected in several seminiferous tubules (Figure 1c,f), indicating that Fas deficiency can rescue testicular germ cells in $W^{N} / W^{N}$ mice. As summarized in Table 1, about $90 \%$ of seminiferous tubules in $W^{N} / W^{N}:$ Fas $^{-1-}$ mice had only Sertoli cells with or without a very few spermatogonia, while we observed a significant

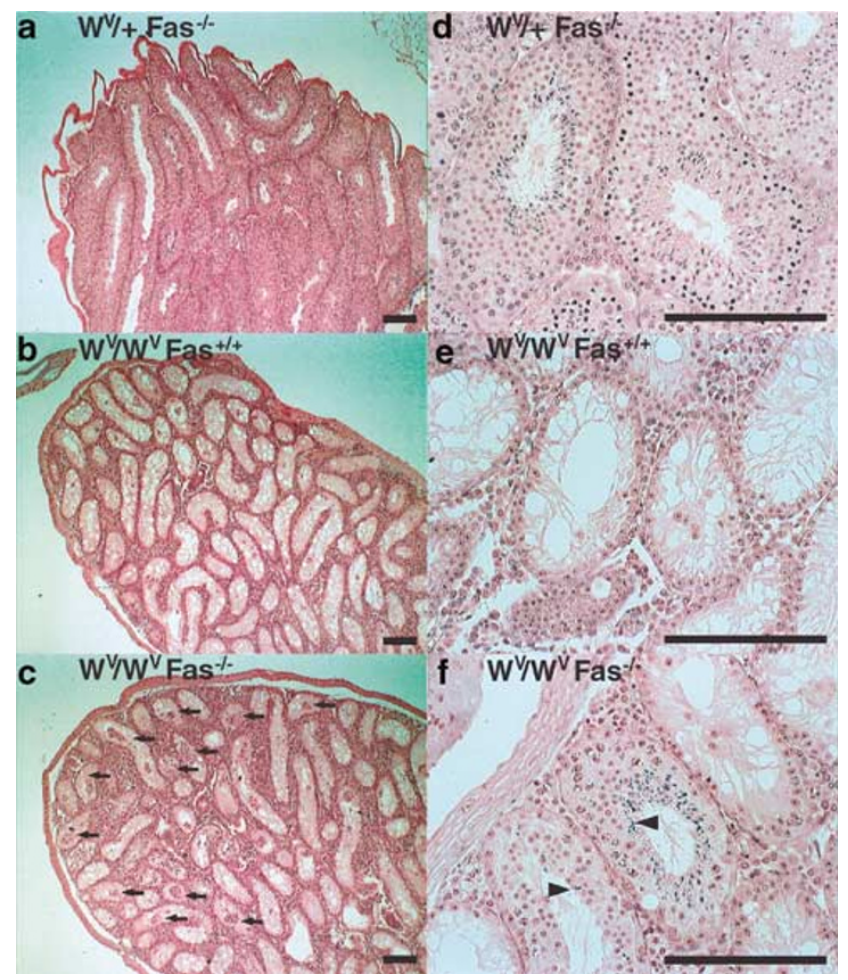

Figure 1 Histological analyses of testes from 8-week-old mutant mice. Sections prepared from testes of $W^{W /+}:$ Fas $^{-l-}(\mathbf{a}, \mathbf{d}), W^{W} W^{W}: \mathrm{Fas}^{+/+}(\mathbf{b}, \mathbf{e})$ and $W^{W} /$ $W^{W}:$ Fas $^{-1-}(\mathbf{c}, \mathbf{f})$ mice were stained with hematoxylin and eosin. Photographs were taken under a phase-contrast microscope at $\times 32(\mathbf{a}-\mathbf{c})$ and $\times 160(\mathbf{d}-\mathbf{f})$. Arrows in (c) show the tubules containing differentiated germ cells indicated by arrowheads in (f). Scale bars correspond to $125 \mu \mathrm{m}$ 


\begin{tabular}{lcccc}
\hline & & \multicolumn{2}{c}{ Percentage of tubules with } \\
\cline { 3 - 5 } Genotype & Number of mice examined & spermatocyte & spermatid & sperm \\
\hline$W^{N} / W^{N}: \mathrm{Fas}^{+/+}$ & 10 & 0 & 0 & 0 \\
$W^{N} W^{N}: \mathrm{Fas}^{-1-}$ & 12 & $9.6 \pm 3.3$ & $5.1 \pm 2.0$ & $4.3 \pm 1.8$ \\
\hline
\end{tabular}

Numerical values show the percentage (mean \pm S.D.) of tubules containing spermatocytes, spermatids or sperm. The mean \pm S.D. was counted under the microscope from histological images depicted in Figure 1. Almost all tubules of a testis were examined for counting by analyzing five cross-sections/testis

number of spermatocytes that differentiated into the pachytene stage in the other $10 \%$ of tubules. Further, differentiated spermatids and sperm could be also observed in about $5 \%$ of seminiferous tubules. The seminiferous tubules containing differentiated germ cells at the meiotic or a more advanced stage of spermatogenesis seemed to be located around rather than in the center of the testes of $W^{N} / W^{N}: \mathrm{Fas}^{-1-}$ mice (Figure 1c). However, we could not detect sperm in the epididymis of $W^{N} / W^{N}: \mathrm{Fas}^{-1-}$ mice by histological analysis (data not shown). Taking all the results into consideration, Fas was shown to be involved in the degeneration of testicular germ cells in $W^{N}$ mutant mice lacking signals from Kit, while other signals might also play a role in the degeneration.

We also examined the propagative activity of $W^{N} / W^{N}: \mathrm{Fas}^{-1-}$ male mice. However, we observed no fertility in $W^{N} W^{N}: \mathrm{Fas}^{-1-}$ male mice mating with wild-type females. The number of undegenerated germ cells and/or differentiated sperm in the double-mutant mice might be too small for fertilization.

\section{Histological analysis of ovaries in the double- mutant mice}

Female gonads were also analyzed in $W^{N /+}:$ Fas $^{-1-}, W^{N /}$ $W^{N}: \mathrm{Fas}^{+/+}$and $W^{N} / W^{N}: \mathrm{Fas}^{-1-}$ mice. Figure 2 shows the results of a histological analysis of ovaries in 4-week-old animals. Ovaries of $W^{N} /+: \mathrm{Fas}^{-/-}$mice displayed a normal histology, where oocytes and follicles at various stages of development were detected (Figure 2a,d). This phenotype of $W /+: \mathrm{Fas}^{-1-}$ mice is similar to that of Ipr mice, which exhibit a spontaneous loss of function in the Fas gene. On the other hand, ovaries of $W^{N} / W^{N}:$ Fas $^{+/+}$mice were shown to be only very small (Figure $2 \mathrm{~b}, \mathrm{e})$, with no oocytes or follicles. Importantly, in ovaries of $W^{N} / W^{N}:$ Fas $^{-1-}$ mice, we detected primary follicles, growing follicles and Graffian follicles with oocytes (Figure 2c,f). Thus, Kit deficiency affected the gametogenesis of female gonads more than male gonads in younger mice, and inactivation of Fas resulted in the diminution of the degeneration of oocytes and follicles in the Kit-deficient ovaries. Results for ovaries are summarized in Table 2. They clearly indicate that loss of function of Fas prevents the degeneration of germ cells in both male and female gonads of $W^{N} / W^{N}$ mice.

Although $W^{N} / W^{N}: \mathrm{Fas}^{-1-}$ female mice were examined in terms of their fertility, they did not become pregnant (data not shown). In addition, oocytes of $W^{N} / W^{N}: \mathrm{Fas}^{-1-}$ mice were shown to be impaired with aging, and most of the oocytes degenerated in the ovary of 8-week-old $W^{N} / W^{N}:$ Fas $^{-1-}$ female mice (data not shown). All the results indicate that Fas is involved in the degeneration of oocytes in 4-week-old $W^{2}$ /

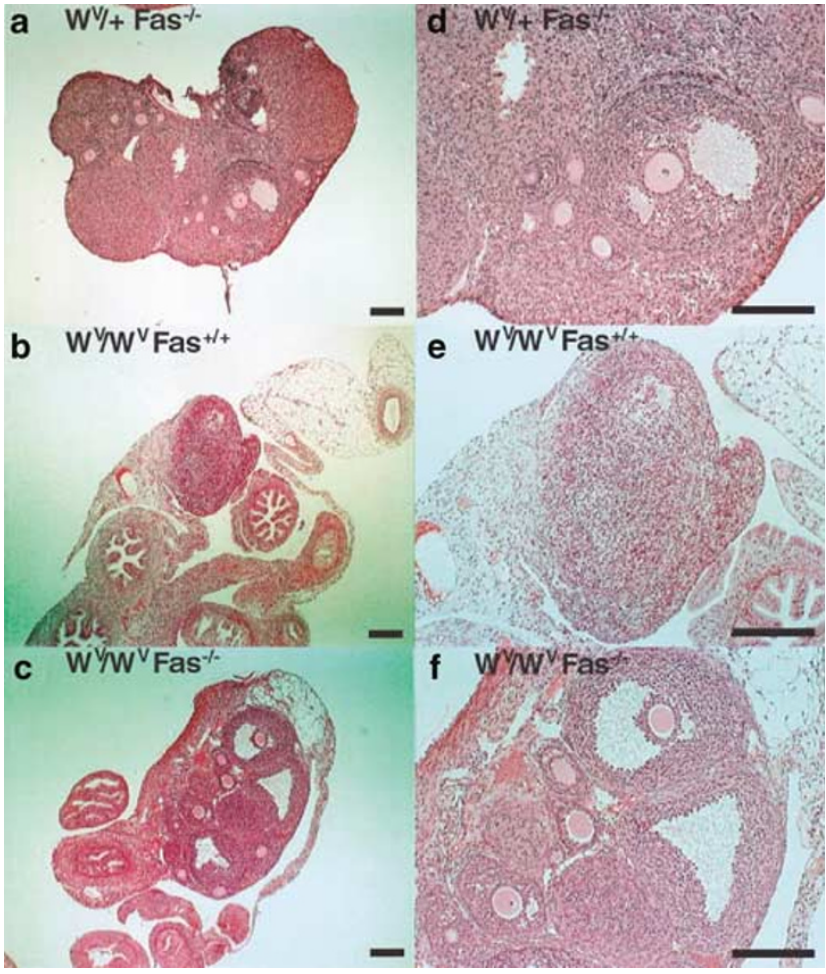

Figure 2 Histological analyses of ovaries isolated from 4-week-old mutant mice. Sections of ovaries of $W^{W /+}:$ Fas $^{-1-}(\mathbf{a}, \mathbf{d}), W^{N} W^{W}: \mathrm{Fas}^{+/+}(\mathbf{b}, \mathbf{e})$ and $W^{2} /$ $W^{W}:$ Fas $^{-l-}$ (c and f) mice were stained with hematoxylin and eosin. Photographs were taken under a phase-contrast microscope at $\times 32(\mathrm{a}-\mathrm{c})$ and $\times 80(\mathbf{d}-\mathbf{f})$. Scale bars correspond to $125 \mu \mathrm{m}$

Table 2 Histological data of ovaries from 4-week-old mice

\begin{tabular}{lcc}
\hline Genotype & $\begin{array}{c}\text { Number of mice } \\
\text { examined }\end{array}$ & $\begin{array}{c}\text { Number of oocytes } \\
\text { in an ovary }\end{array}$ \\
\hline$W^{N} / W^{N}: \mathrm{Fas}^{+/+}$ & 8 & 0 \\
$W^{N} / W^{N}: \mathrm{Fas}^{-1-}$ & 12 & $6.6 \pm 5.1$ \\
\hline
\end{tabular}

Numerical values show the number (mean \pm S.D.) of differentiated oocytes (oocytes in secondary follicles and Graffian follicles) in an ovary. The mean \pm S.D. of oocytes/ovary was counted under the microscope from serial cross sections of the entire ovary. The numbers of differentiated oocytes in wildtype and Fas ${ }^{-1-}$ mice were essentially the same (about 50/ovary) as described previously. ${ }^{35}$

$W^{\text {}}: \mathrm{Fas}^{-1-}$ female mice, while mechanisms other than Fasmediated apoptosis might play a role in the infertility and the degeneration of oocytes of 8-week-old $W^{N} W^{N}:$ Fas $^{-1-}$ mice. 


\section{In vivo blocking of Kit signals by anti-Kit mAb causes germ cell degeneration in wild-type but not Fas-deficient mice}

We next examined the effects of Fas deficiency on the degeneration of testicular germ cells in another mouse system with suppressed Kit signals. We artificially blocked the Kit signaling pathway through injection of an antagonistic anti-ckit mAb ACK2 into wild-type C57BL/6 and Fas-deficient mice. We analyzed the population of testicular germ cells from both mice after injection of ACK2. It has been demonstrated that differentiating spermatogonia and early preleptotene spermatocytes expressing Kit degenerated after injection of ACK2 which can block the function of Kit. ${ }^{18}$ We examined the testes of the antibody-treated animals by an immunohistochemical method with an anti-germ cell-specific mAb, TRA98, and stained another serial section with Hoechst (Figure 3). At $48 \mathrm{~h}$ after injection of ACK2, most differentiating type $A$ and intermediate spermatogonia had disappeared in the wild-type testes (Figure 3a), although differentiated germ cells and interstitial cells were observed in Hoechst-stained sections (Figure 3c). In contrast, many spermatogonia still existed even after $48 \mathrm{~h}$ in Fas-deficient mice (Figure $3 \mathrm{~b}$ ). These results supported our results for $W^{N} / W^{N}:$ Fas $^{-1-}$ double-mutant male mice (Figure 1 and Table 1) and strongly indicate that Fas is involved in testicular germ cell degeneration induced by defects of Kit signaling.

\section{Expression of Fas in testes from wild-type and homozygous $W^{v} / W^{v}$ mutant mice}

Our data thus suggest that Kit-mediated signals inhibit the Fas-mediated apoptosis-inducing signal. To clarify the molecular mechanism of the Kit-induced inhibition, we analyzed the expression level of Fas because activation of Ras, which must occur downstream of Kit, was previously reported to decrease the expression. ${ }^{48}$ In our case, we speculated that the deficiency of Kit signaling might cause the induction of Fas expression on the germ cells. At first, we analyzed the expression at the RNA level by Northern blot hybridization. We examined total RNA isolated from the testes of 6-week-old wild-type C57BL/6 and homozygous $W^{N} / W^{N}$ mutant mice (Figure 4). Fas transcripts were significantly detected in the testes from $W^{N} / W^{N}$ mutant mice, but we could not detect Fas mRNA in the testes of wild-type mice. This result suggested that Fas is expressed on spermatogonia and/or interstitial cells. Alternatively, the difference in Fas expression might reflect the difference of the cell population in the testes of wildtype and $W^{N} / W^{N}$ mutant mice.

To identify the cell surface expression of Fas, we performed flow cytometric analysis with the anti-Fas mAb Jo-2. Fas expression was examined on the surface of testicular cells prepared from 3- to 4-week-old wild-type C57BL/6 and homozygous $W^{N} W^{N}$ mutant mice. In wild-type testes, few cells expressing Fas were observed, while such cells were detected in $W^{N} / W^{N}$ mutant mice (Figure 5a). Then, we carried out a two-dimensional flow cytometric analysis with the Jo-2 and EE2 mAbs in order to clarify whether Fas is expressed on spermatogonia or not. Previous study demonstrated the expression of EE2 antigen on the germ cell surface; the

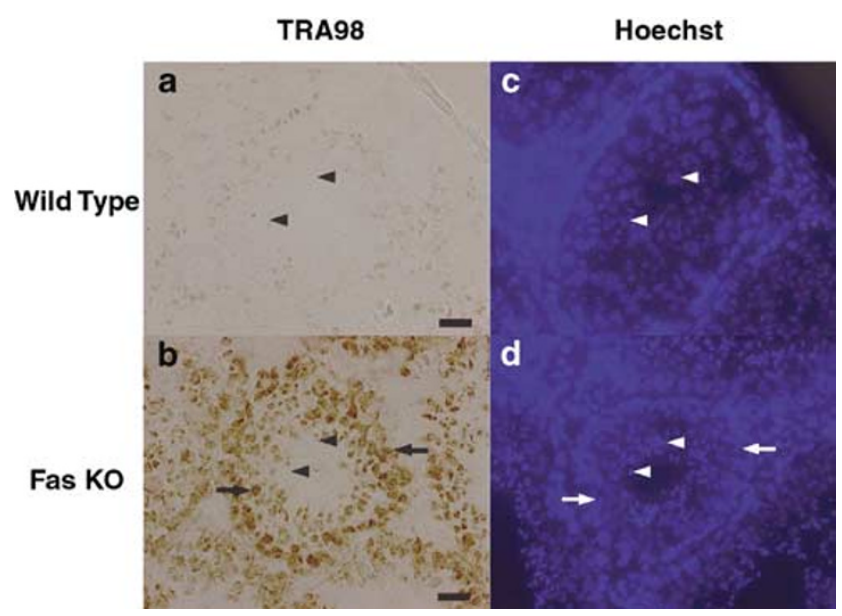

Figure 3 Immunohistochemistry of testes from ACK2-injected adult mice. Frozen sections were prepared from testes of wild-type C57BL/6 mice $(\mathbf{a}, \mathbf{c})$ and Fas $^{-l-}$ mice $(\mathbf{b}, \mathbf{d})$, to which anti-c-kit mAb ACK2 was administered $48 \mathrm{~h}$ earlier, as described in Materials and Methods. The section was then stained with the germ cell-specific mAb TRA98 $(\mathbf{a}, \mathbf{b})$, and another serial section was stained with Hoechst $(\mathbf{c}, \mathbf{d})$. Experiments were repeated five times using different mice and the data presented show representative results. Photographs were taken under a phase-contrast microscope at $\times 160$. Arrows and arrowheads show spermatogonia and differentiated haploid spermatids, respectively. Scale bars correspond to $25 \mu \mathrm{m}$
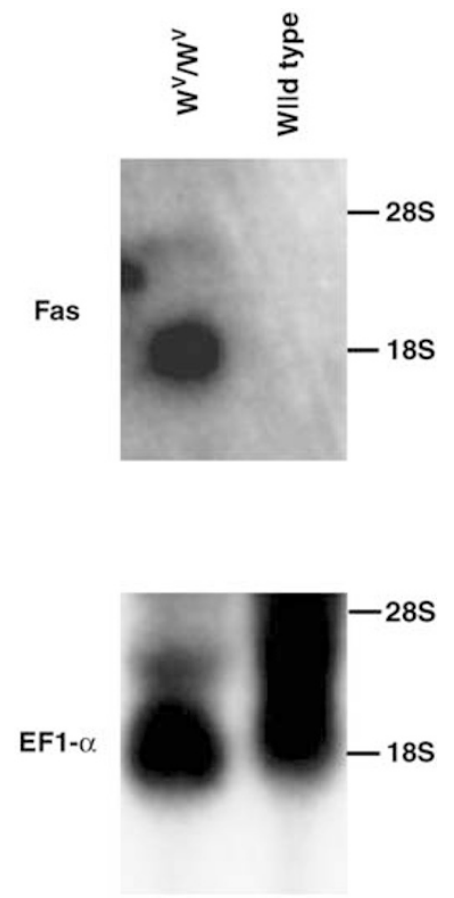

Figure 4 Northern blot analysis of Fas transcripts in testes. Northern blotting was carried out with total RNA isolated from testes of 5- to 6-week-old wild-type C57BL/6 and $W^{N} / W^{N}$ mutant mice as described in Materials and Methods using ${ }^{32}$ P-labeled mouse Fas (upper panel) and human EF1- $\alpha$ (lower panel) cDNAs as DNA probes.

expression was predominant prior to meiosis, and gradually decreased as the differentiation proceeded. ${ }^{49}$ EE2-bright cells correspond to type $A$ and primitive spermatogonia, while EE2intermediate cells correspond to intermediate and type B 
a

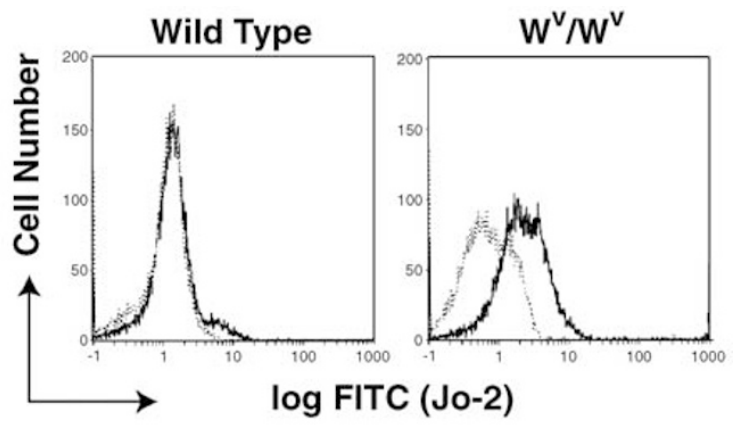

b
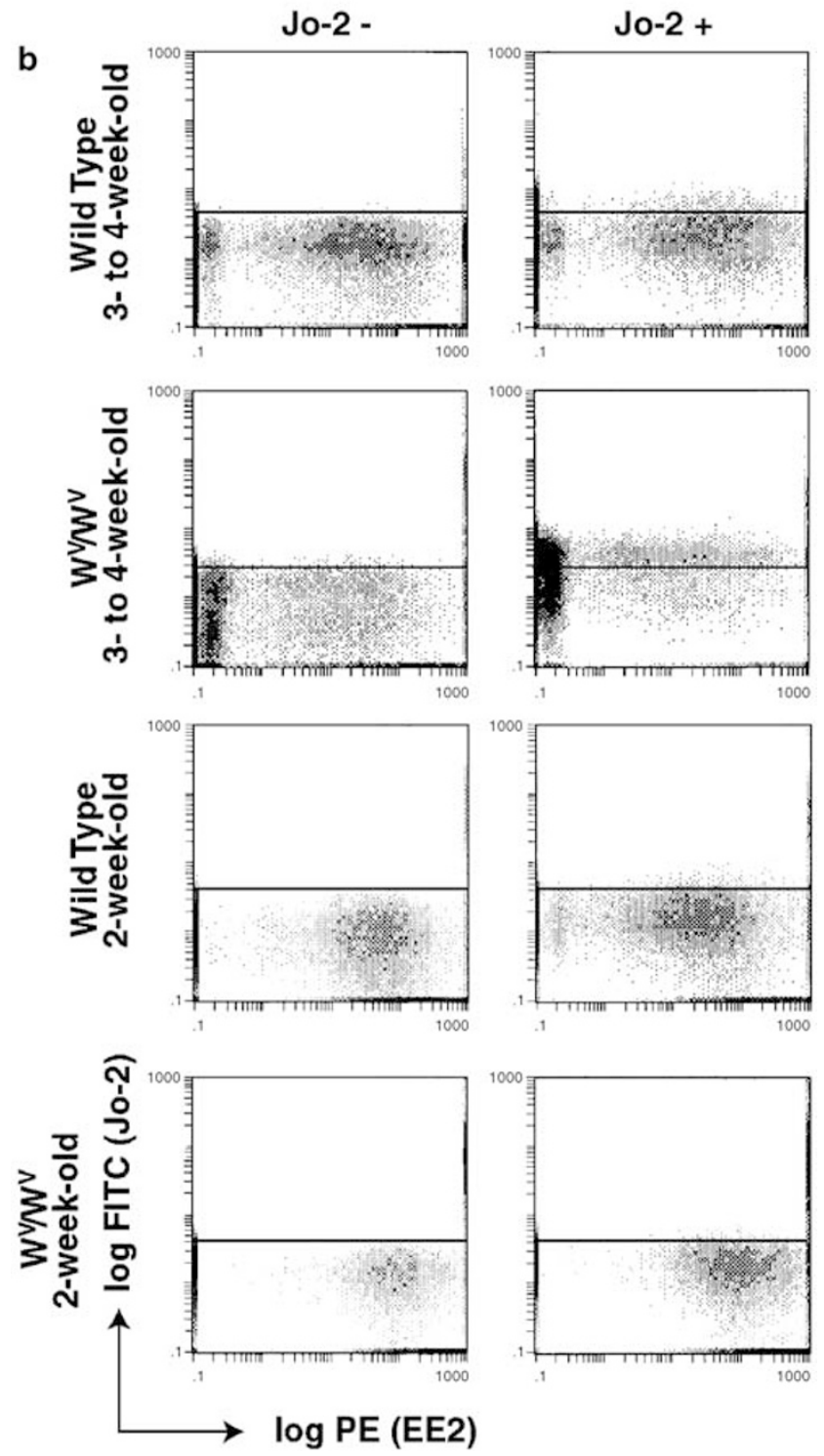

spermatogonia, preleptotene, leptotene and zygotene spermatocytes. EE2-negative cells correspond to pachytene spermatocytes or cells in the more advanced stages of spermatogenesis and interstitial cells. Flow cytometric analysis clearly indicated that Fas was significantly expressed on EE2-positive cells in $W^{N} / W^{N}$ mutant mice although little expression of Fas was detected on EE2-positive cells in
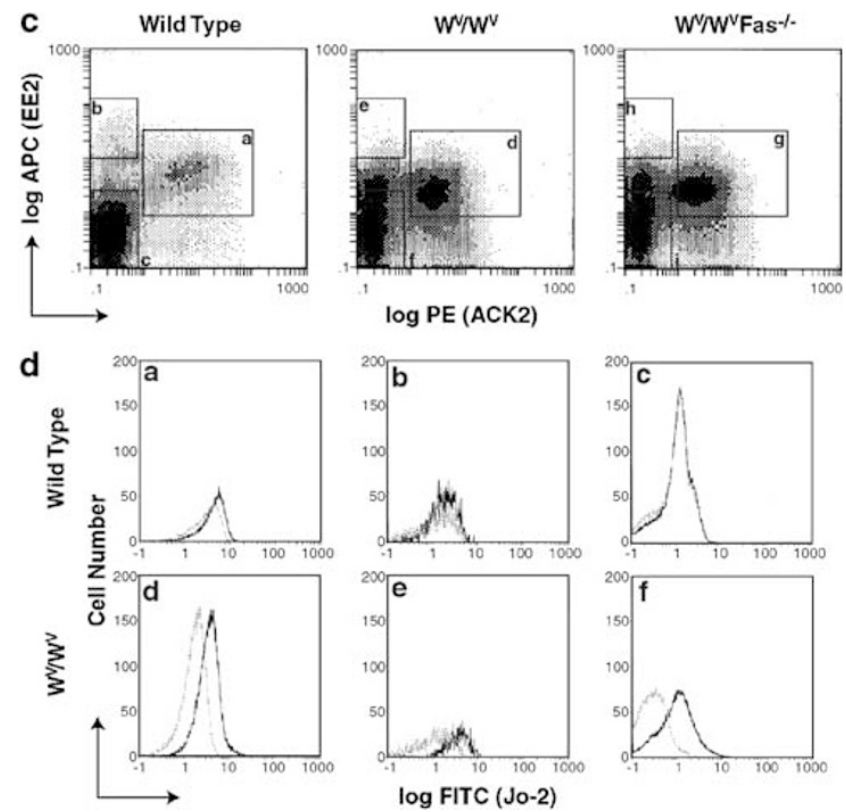

Figure 5 Flow cytometric analyses of Fas expression on mouse testicular germ cells. (A) Single-cell suspensions isolated from testes of 3- to 4-week-old wildtype C57BL/6 mice (left panel) and $W^{N} / W^{N}$ mutant mice (right panel) were stained with (solid lines) or without (dotted lines) FITC anti-Fas mAb Jo-2. (B) Testicular cells of 3- to 4-week-old or 2-week-old wild-type C57BL/6 mice and $W^{N} / W^{N}$ mutant mice were stained with PE-anti-testicular germ cell mAb EE2, together with (right panels) or without (left panels) FITC-Jo-2. (C) Single-cell suspensions isolated from testes of 3- to 4-week-old wild-type C57BL/6 mice (left panel), $W^{W} / W^{N}$ mutant mice (center panel) and $W^{N} W^{N}:$ Fas $^{-1-}$ mice (right panel) were stained with EE2 and ACK2. The squares, indicated as a, $\mathrm{d}$ and $\mathrm{g}$, correspond to spermatogonia; $b, e$ and $h$ to primitive spermatogonia; and $c, f$ and $i$ to interstitial cells and welldifferentiated germ cells. (D) Fas expression on testicular cells in the squares in (C). Cells were stained with (solid lines) or without (dotted lines) FITC Jo-2. All experiments were repeated five times, and the data presented show representative results

wild-type mice (Figure 5b). We then examined germ cells of 2week-old mice, and found the induction level of Fas expression in 2-week-old than 3- to 4-week-old $W^{N} / W^{N}$ mutant mice (Figure $5 b$ ). Fas expression was indicated to be upregulated in testicular germ cells of 3- to 4-week-old mice mainly because of a deficiency of Kit.

To clearly distinguish expression levels of Fas between SCF-dependent and -independent spermatogonia, we carried out flow cytometric analyses by triple staining with EE2, ACK2 and Jo-2. Figure $5 \mathrm{c}$ shows the results of two-dimensional flow cytometric analyses with EE2 and ACK2 in wild-type (left panel), $W^{N} / W^{N}$ mutant (center panel) and $W^{N} W^{N}: \mathrm{Fas}^{-1-}$ double-mutant (right panel) mice. Kit-positive and EE2positive cells (squares a, $d$ and g) correspond to spermatogonia that require SCF-induced Kit signals for differentiation. Kit-negative and EE2-bright cells (squares b, e and h) correspond to primitive spermatogonia such as testicular stem cells which have the ability to self-proliferate. Kitnegative and EE2-negative cells (squares $c$, $f$ and $i$ ) correspond to Sertoli cells and pachytene spermatocytes or more advanced stages of spermatogenesis. In $W^{N} / W^{N}$ mutant mice, primitive spermatogonia, encircled with the square e, were decreased in number when compared with those of wildtype mice. In $W^{N} / W^{N}: \mathrm{Fas}^{-/-}$double-mutant mice, however, a 
drastic recovery of primitive spermatogonia was not observed. Although the percentage of wild-type spermatogonia requiring Kit signals for differentiation, encircled with the square a (containing $10 \%$ of total cells), was about one-third of that of $W^{N} / W^{N}$ spermatogonia (square d, 24\%), the total cell number of spermatogonia/testis in wild-type mice was more than six times that in $W^{N} / W^{N}$ mutant mice, because total cell number/testis for cytofluorometric analysis in wild-type mice was more than 20 times that in $W^{N} / W^{N}$ mutant mice. Interestingly, Fas deficiency increased the number of spermatogonia requiring Kit signals for differentiation more than two-fold when compared with that of $W^{N} / W^{N}$ mutant mice, because (1) the percentage of spermatogonia requiring Kit signals for differentiation in $W^{N} / W^{N}$ and $W^{N} / W^{N}:$ Fas $^{-1-}$ mutant mice was comparable (square d, $24 \%$, and square g, $29 \%$, respectively) and (2) total cell number/testis for cytofluorometric analysis in $W^{N} / W^{N}:$ Fas $^{-1-}$ mice was more than two times that in $W^{N} / W^{N}$ mutant mice.

Next, we examined Fas expression on Kit-positive and EE2-positive cells, Kit-negative and EE2-bright cells and Kitnegative and EE2-negative cells encircled with the squares a$f$ in Figure $5 c$ (Figure $5 d$ ). $W^{N} / W^{N}$ mutant mice were shown to significantly express Fas in all the testicular cells, while wildtype mice expressed little Fas in any testicular cells.

All the results indicated that the expression of Fas on germ cells was upregulated in the testes of $W^{N} / W^{N}$ mutant mice, and germ cell degeneration induced by defects in the Kit signaling system was suggested to be caused by activation of the Fasmediated signaling pathway.

\section{SCF downregulates Fas expression on Kit- expressing NIH3T3 cells}

To confirm the downregulation of Fas by Kit-induced signals, we examined the effects of SCF on Kit-expressing cells in vitro. We transfected c-kit cDNA into NIH3T3 cells and established several Kit-positive stable clones. Then, we analyzed the expression of Fas on these clones by flow cytometry after treatment with $10 \mu \mathrm{g} / \mathrm{ml}$ of mouse recombinant SCF for $48 \mathrm{~h}$. A significant decrease of Fas was detected on the Kit-expressing stable clone $\mathrm{NIH}-\mathrm{K} 11$ but not parental NIH3T3 cells after treatment with SCF (Figure 6a,b). The other Kit-positive stable clones showed essentially similar characteristics to those of $\mathrm{NIH}-\mathrm{K} 11$ cells (data not shown). These results directly show that the Kit signal induces the downregulation of Fas.

We then examined which downstream signal of Kit plays a role in the downregulation of Fas expression. Since the downregulation was speculated to be induced by survival signals mediated through Kit, we focused on two signaling pathways downstream of Kit, PI3K/Akt and Ras/MEK/ERK. Activation of the Ras/MEK/ERK pathway was reported to inhibit Fas-mediated apoptosis, ${ }^{50}$ while activation of PI3K/Akt pathway was suggested to suppress the expression level of cell surface Fas. ${ }^{48}$ In addition, Kit-mediated activation of the PI3K/Akt pathway was demonstrated to be significant in gametogenesis. ${ }^{51,52}$ We analyzed the effects of two kinds of inhibitors that specifically prevent Kit-mediated signaling: the PI3K-specific inhibitor wortmannin and the MEK1/2-specific a

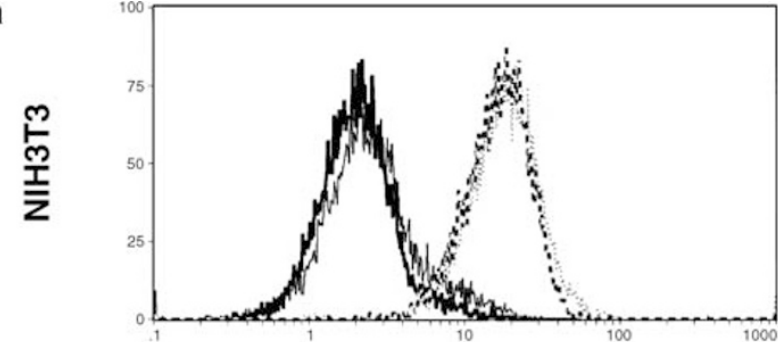

b

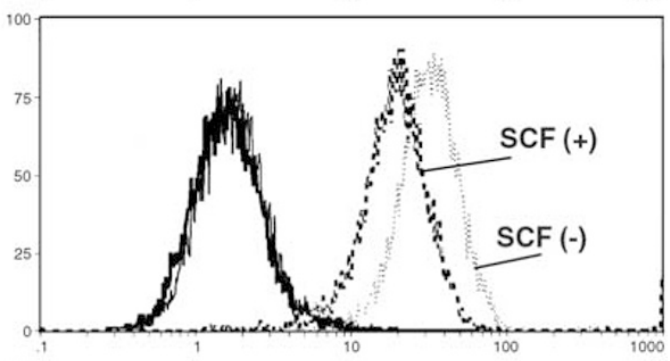

C

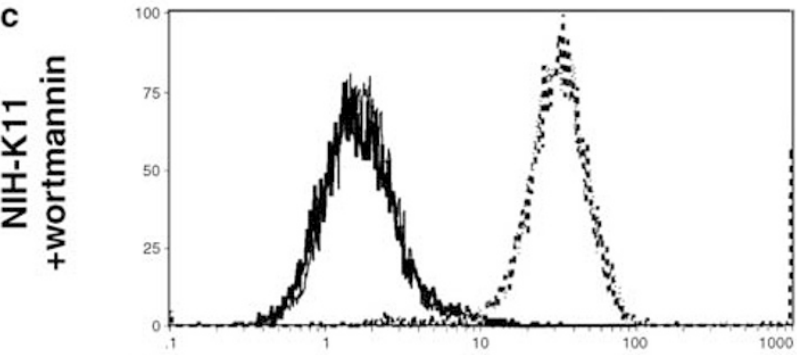

d

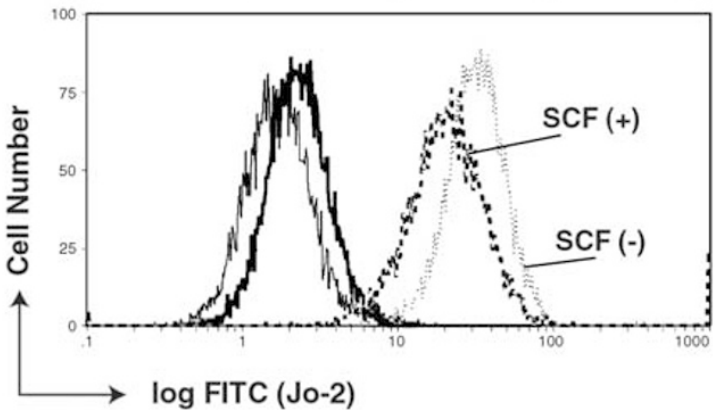

Figure 6 Flow cytometric analyses of Fas expression on SCF-treated fibroblasts expressing exogenous Kit. Parental NIH3T3 (a) and Kit-expressing stable clone NIH-K11 (b) cells were stimulated with (bold lines) or without (fine lines) $10 \mathrm{ng} / \mathrm{ml}$ of SCF for $48 \mathrm{~h}$ and then stained with (dotted lines) or without (solid lines) FITC-Jo-2. NIH-K11 cells were also stimulated with SCF for $48 \mathrm{~h}$ in

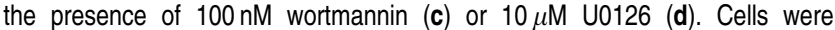
pretreated with each inhibitor for $30 \mathrm{~min}$ prior to stimulation with SCF. Experiments were repeated five times, and the data presented show representative results

inhibitor U0126. These inhibitors were added to the culture medium of $\mathrm{NIH}-\mathrm{K} 11$ cells together with SCF and Fas expression was examined $48 \mathrm{~h}$ later with a flow cytometer (Figure $6 \mathrm{c}$ and d). Downregulation of Fas was suppressed by the treatment with wortmannin, while U0126 showed no significant effect. Similar results were obtained with the PI3K inhibitor LY294002 and MEK1 inhibitor PD98059 (data not shown). Thus, PI3K inhibitors but not MEK inhibitors blocked the downregulation of Fas by SCF.

To biochemically detect the activation of downstream signaling molecules of Kit, which was inhibited by wortmannin 


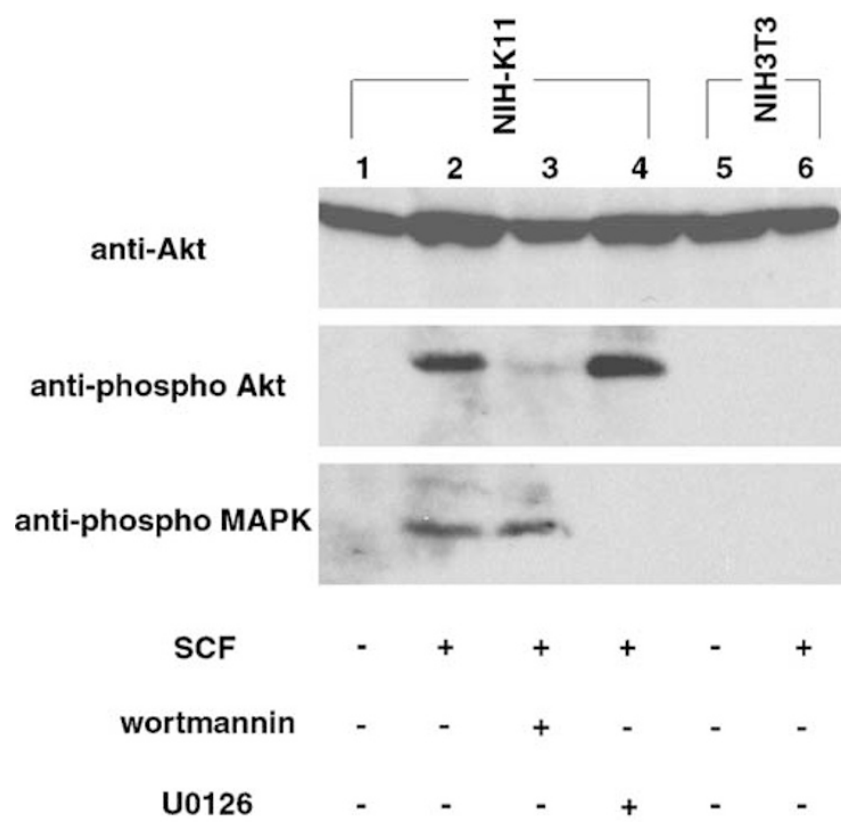

Figure 7 Immunoblot analyses of SCF-treated NIHK-11 and NIH3T3 cells. Cells were precultured without serum for $12 \mathrm{hr}$ before treatment with $10 \mathrm{ng} / \mathrm{ml}$ of SCF together with or without wortmannin or U0126. Cells were pretreated with each inhibitor for $30 \mathrm{~min}$ prior to SCF stimulation. Akt, Akt phosphorylated at Thr 308 and phosphorylated MAPK (ERK) were detected with anti-Akt (upper panel), antiphospho Akt (center panel) and anti-phospho MAPK (lower panel) antibodies, respectively

or U0126, we examined the phosphorylation of Akt and ERK, which are downstream molecules of PI3K and MEK, respectively. Immunoblot analyses for Akt and ERK were carried out using antiphospho-Akt (Thr308) and antiphosphop44/42 MAPK antibodies, respectively (Figure 7). After $15 \mathrm{~min}$ stimulation of NIH-K11 (lanes 1-4) and NIH3T3 cells (lanes 5, 6) with $10 \mathrm{ng} / \mathrm{ml}$ of SCF, the phosphorylation of Akt and ERK was observed in SCF-stimulated NIHK-11 cells (lane 2), but in neither unstimulated $\mathrm{NIH}-\mathrm{K} 11$ (lane 1) nor parental NIH3T3 cells (lanes 5, 6). In addition, the SCF-induced phosphorylation of Akt and ERK was canceled by addition of wortmannin (lane 3) and U0126 (lane 4), respectively. Thus, the SCF/Kitinduced downregulation of Fas was shown to correlate well with the activation of PI3K/Akt.

\section{Akt plays an important role in downregulation of Fas expression on NIH3T3 cells}

Figures 6 and 7 clearly show that $\mathrm{PI} 3 \mathrm{~K}$ is involved in the regulation of Fas expression. To clarify the downstream signaling molecule of $\mathrm{PI} 3 \mathrm{~K}$ regulating Fas expression, we transfected a constitutively active Akt (caAkt; HA-m $\Delta 4$ 129Akt) into NIH3T3 cells and analyzed Fas expression by flow cytometry (Figure 8). GFP-expression vector was cotransfected with a caAkt or control vector, and Fas expression in GFP-positive cells was analyzed. The expression level of Fas on caAkt transfectants was significantly lower than that of cells transfected with the control vector. Thus,
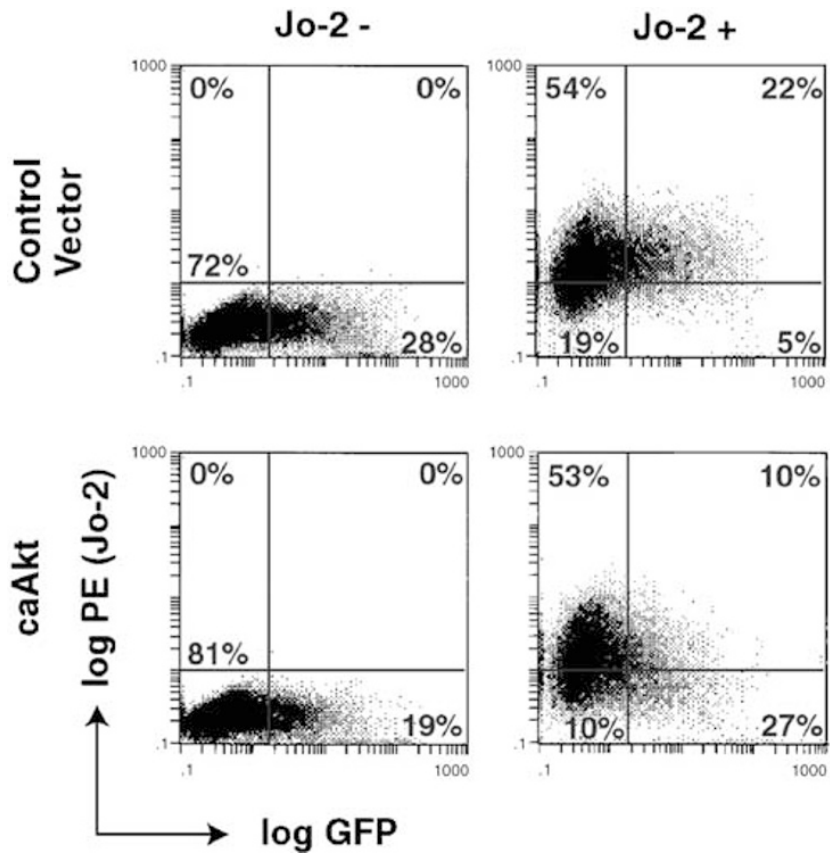

Figure 8 Effect of constitutive active Akt on expression of Fas. Control vector (upper panels) or the expression vector for constitutive active Akt (lower panels) was cotransfected with the expression vector for GFP into NIH3T3 cells. After $48 \mathrm{hr}$ cultivation, cells were stained with control-PE-IgG (left panels) or PEconjugated Jo-2 (right panels), and analyzed by flow cytometry. The proportion (\%) of separated respective cells into four parts is shown in the figure. Experiments were repeated five times, and the data presented show representative results

activation of Akt downregulates Fas expression on $\mathrm{NIH} 3 \mathrm{~T} 3$ cells.

Taking these results together, we conclude that stimulation of the Kit receptor downregulates Fas expression by activating the PI3K/Akt pathway in not only exogenous Kit-expressing fibroblasts in vitro but also germ cells in gonads in vivo.

\section{Discussion}

In this study, we demonstrated that a failure of Kit signaling induces activation of the Fas system in both male and female gonads by analyzing $W^{N} / W^{N}$, Fas ${ }^{-1}$ and double-mutant mice. Further, we verified that the PI3K/Akt signaling pathway downstream of Kit regulates expression of Fas. From this evidence, we proposed that crosstalk occurs between Kitmediated and Fas-mediated signaling pathways in the mouse gonads.

In the male gonads of $W^{N} / W^{N}: \mathrm{Fas}^{-1-}$ mice, we observed differentiating germ cells in approximately $10 \%$ of seminiferous tubules, but could not detect a recovery of germ cells in all seminiferous tubules (Figure 1). These results indicate that Fas is necessary but not sufficient to induce germ cell apoptosis in $W^{V}$ mutant mice, and other factors must be involved in the loss of germ cells in $W^{v}$ mutant mice. Recently, a deficiency of p53 was reported to rescue germ cell degeneration in $W^{v} / W^{v}$ mice. ${ }^{53}$ Although these $W^{v} / W^{v}: p 53^{-1-}$ double-mutant mice showed propagative activity, their 
sperm counts were less than $7 \%$ of those in wild-type mice. Inactivation of p53 may not be sufficient to rescue germ cell degeneration induced by a failure of Kit signaling. We suppose that both Fas and p53 work cooperatively as an executioner in germ cell death. Our hypothesis is supported by a previous report describing that Fas was responsible for the p53-independent germ cell apoptosis in response to heat stress in Ipr/lpr.p53 ${ }^{-1-}$ double-mutant mice. ${ }^{54}$ Thus, both Fasand p53-dependent signaling pathways play a role in the apoptosis of germ cells.

Interestingly, a deficiency of p53 did not rescue oocytes of $W^{N} W^{N}$ mice from degeneration. ${ }^{53}$ In contrast, our $W^{N} /$ $W^{N}:$ Fas $^{-1-}$ mice displayed an apparently normal oogenesis and folliculogenesis even though the Kit signaling was defective (Figure 2). These results indicate that loss of function of Fas, but not that of p53, leads to the recovery of both oocytes and granulosa cells in $W^{N}$ mutant mice. Many previous reports, including ours, demonstrated expression of Fas on granulosa cells. ${ }^{31-38}$ A few reports suggested expression of Fas on oocytes ${ }^{32,38,39}$ although we could not detect it. On the other hand, Kit expression was shown to be restricted on oocytes but not on granulosa cells in follicles, ${ }^{13,18,55}$ while deficiency of Kit leads to Fas-induced loss of granulosa cells as well as oocytes. We wondered why Kitpositive and Fas-negative oocytes and Kit-negative and Faspositive granulosa cells are similarly degenerated in $W^{N}$ mutant mice. In oocytes, failure of Kit signaling might induce Fas expression. To explain the loss of granulose cells, two previous reports are helpful, which insisted on the presence of paracrine factor(s) moving between oocytes and granulosa cells in the follicles. ${ }^{55,56}$ Loss of the paracrine factor(s) from oocytes in Kit-defective mice may activate Fas-mediated apoptotic signals in granulosa cells.

Kit signals are essential not only in gametogenesis but also in hematopoiesis and melanogenesis. Therefore, we examined bone marrow cells isolated from $W^{N} / W^{N}: \mathrm{Fas}^{+/+}$and $W^{N} /$ $W^{N}: \mathrm{Fas}^{-1-}$ mice, but we could not observe a noticeable difference in their cell populations by flow cytometric analyses (data not shown). Moreover, Fas expression was previously reported on granulocytes expressing Kit. ${ }^{57}$ Thus, Fas expression is not regulated by Kit-mediated signals in hematopoietic cells. In addition, our double-mutant mice displayed the same coat color as $W^{N} / W^{N}: \mathrm{Fas}^{+/+}$mice, suggesting that inactivation of Fas has no significant effect on the survival of melanocytes. Thus, the downregulation of Fas expression by Kit-mediated signals is suggested to be a cell type-specific event. This might explain the moderate level of SCF-induced downregulation of Fas in Kit-expressing fibroblasts (Figure 6).

In this study, we demonstrated the existence of crosstalk between Fas-mediated apoptotic signals and Kit-mediated survival signals. In vivo, Fas expression was upregulated on Kit-deficient $W^{N}$ spermatogonia (Figure 5). On 4-week-old $W^{N}$ spermatogonia, which soon undergo apoptosis, the expression of Fas is strong, while on 2-week-old $W^{N}$ spermatogonia, which survive for some time, it is negligible. These results correlate well with the germ cell apoptosis associated with the aging of $W / W^{N}$ mutant mice. From the results of twodimensional flow cytometric analyses with EE2 and ACK2, the number of primitive spermatogonia was shown to dramatically decrease in $W^{N} / W^{N}$ mutant mice. While primitive spermatogonia of $W^{N} / W^{N}$ mutant mice expressed Fas, the number of these cells in $W^{N} / W^{N}:$ Fas $^{-1-}$ double-mutant mice recovered only slightly. It is considered that Fas may not be directly involved in the degeneration of primitive spermatogonia in $W^{N} / W^{N}$ mutant mice, and other factor(s) might contribute to the loss. In contrast, the number of SCF-requiring spermatogonia recovered in $W^{N} / W^{N}: \mathrm{Fas}^{-1-}$ double-mutant mice compared with $W^{N} / W^{N}$ mutant mice. All the results indicated that a defect in Fas can rescue SCF-dependent spermatogonia from apoptosis, resulting in an increase in the number of more differentiated cells, although Fas deficiency cannot rescue primitive spermatogonia.

In addition, we also showed that Fas is downregulated in vitro on stimulation with SCF in Kit-expressing NIH3T3 cells (Figure 6). Our in vitro analyses with inhibitors for PI3K or transfectants expressing caAkt clearly verified the correlation between the activation of Akt and downregulation of Fas expression (Figures 6-8). The significance of the Kitmediated PI3K/Akt signaling pathway in gametogenesis was previously demonstrated by analyzing mutant Kit knockin mice. ${ }^{51,52}$ These mutant mice, expressing mutated Kit at Tyr719 which cannot interact with the p85 subunit of PI3K, were shown to be defective in spermatogenesis and oogenesis but not in hematopoiesis and melanogenesis. These results coincided well with our results in this study. In addition, Akt1-deficient mice were recently generated and showed a similar phenotype to that observed in the knockin mice of the Kit mutant. ${ }^{58}$ Thus, the PI3K/Akt signaling pathway via Kit is essential for the survival of testicular germ cells and oocytes, which suppresses Fas-mediated apoptotic signaling by downregulating the expression of Fas in the gonads.

In this study, we demonstrated that Fas expression is downregulated via the activation of PI3K/Akt signaling. This result coincided with a previous report indicating downregulation of Fas on the activation of Ras/PI3K/Akt in NIH3T3 cells. ${ }^{48}$ However, several lines of evidence indicated that the PI3K/Akt signaling pathway negatively controls apoptosis by regulating multiple signaling molecules. By inactivating a forkhead transcription factor, FKHRL-1, Akt was reported to downregulate $\mathrm{Fas}$ ligand and upregulate expression of $\mathrm{c}$ FLIP, which is known as an antiapoptotic molecule against Fas-induced apoptosis. ${ }^{59,60}$ As we have not shown the regulation of these target molecules by activated PI3K/Akt in this study, it is necessary to clarify them with further studies.

We used NIH3T3 cells to investigate the downregulation of Fas by Kit-mediated and caAkt-induced signals (Figures 6 and 8). Further, Ras and its downstream molecule PI3K were reported to downregulate Fas expression, although activation of Akt was not shown. ${ }^{48}$ However, we could not detect a noticeable reduction of endogenous Fas expression on Balb3T3 cells expressing caAkt as described in a previous report, where we showed that Fas-mediated apoptosis was strongly inhibited by treatment with basic FGF, a ligand for another RTK, through inhibiting intracellular signals via Fas by activation of ERK ${ }^{50}$ These results indicate that inhibitory mechanisms for Fas-mediated apoptosis are regulated by multiple signaling molecules including Akt and ERK, which affect not only the Fas expression level but also the intracellular signaling pathway via Fas. Kit-mediated signals 
might inhibit Fas-mediated apoptosis both in vivo and in vitro by not only suppressing Fas expression but also blocking the intracellular signaling pathway via Fas.

In this study, we revealed the negative regulation of Fasmediated signaling by survival signals induced by Kit/SCF through in vivo and in vitro analyses of $W^{N}$ mutant mice and fibroblasts, respectively. Our results provide a clue to the relation between various survival signals and death signals.

\section{Materials and Methods}

\section{Materials and antibodies}

The nylon membrane Hybond-N was purchased from Amersham Bioscience, PI3K inhibitors wortmannin and LY294002 from SIGMA and Cell Signaling, respectively, the MEK1/2 inhibitor U0126 and MEK1 inhibitor PD98059 from Cell Signaling and the polyvinylidene difluoride (PVDF) membrane Immobilon from Millipore.

Monoclonal antibodies EE2 ${ }^{49}$ and TRA98 ${ }^{61}$ that recognize testicular germ cells and anti-c-kit mAb ACK2 ${ }^{62}$ were prepared as described previously. Fluorescein isothiocyanate (FITC)- and phycoerythrin (PE)conjugated anti-Fas mAb Jo-2 were purchased from BD-Pharmingen. Horseradish peroxidase (HRP)-conjugated anti-Rat IgG Ab was from Cappel, biotin-conjugated anti-rat $\kappa+\lambda$ light chains mAb from Sigma, HRPconjugated anti-mouse Ig from Amersham Bioscience, PE- and APCconjugated avidin from BD-Pharmingen and PE-conjugated ACK2 from eBioscience. Anti-Akt mAb, anti-Phospho-Akt (Thr308) $\mathrm{Ab}$ and antiPhospho-p44/42 MAPK mAb and HRP-linked anti-rabbit IgG Ab were purchased from Cell Signaling.

\section{Mice}

$W^{N} / W^{N}: F^{-1-}$ mice were generated by intercrossing heterozygous $W^{N /+}$ mutant mice (SLC, Shizuoka, Japan) with Fas-deficient mice ${ }^{63}$ having the same $\mathrm{C} 57 \mathrm{~B} / 6$ background. A Fas-deficient $\mathrm{C} 57 \mathrm{~B} / 6$ background was generated by backcrossing seven times with $\mathrm{C} 57 \mathrm{~B} / 6$ mice. The genotype of the Fas mutants was identified by PCR assay with DNA isolated from tails. The $W^{N}$ mutation was distinguished by coat color. For the dissection of reproductive organs, mice were killed using carbon dioxide gas.

\section{Histological analysis}

Testes and ovaries dissected from mice were fixed overnight in Bouin's solution, embedded in paraffin after dehydration, and cut at $5 \mu \mathrm{m}$. Sections were stained with hematoxylin and eosin according to standard procedures.

\section{Administration of anti-c-kit mAb ACK2}

To block c-kit function, $100 \mu \mathrm{g} /$ mouse of purified anti-c-kit mAb ACK2 was intravenously injected into adult (8- to 12-week-old) mice as described previously. ${ }^{18}$ For a control, the same volume of phosphate-buffered saline (PBS) was injected.

\section{Immunohistochemistry}

Dissected testes were embedded in an O.C.T compound (Tissue-Tec, Sakura, Tokyo, Japan), frozen quickly in liquid nitrogen, and sectioned at $8 \mu \mathrm{m}$ with a cryostat (Carl Zeiss). Sections were fixed for $30 \mathrm{~min}$ in PBS containing $4 \%$ paraformaldehyde at room temperature, and then stained with the germ cell-specific mAb TRA98 as follows. The sections were preincubated in PBS containing 1\% goat serum for $1 \mathrm{~h}$, and then incubated with TRA98 in PBS containing 3\% skimmed milk and 0.1\% Tween 20 (PBS-MT) at room temperature for $1 \mathrm{~h}$. After three washes with PBS containing $0.1 \%$ Tween 20 (PBS-T), the sections were incubated with HRP-conjugated anti-Rat IgG (1:1000) in PBS-MT for $2 \mathrm{~h}$. After three more washes with PBS-T, samples were developed using a metal-enhanced diaminobendizine (DAB) substrate kit (PIERCE).

\section{Northern blot analysis}

Cellular total RNA was prepared from testes of C57BL/6 and $W^{N} W^{N}$ mutant mice using ISOGEN (Nippon Gene, Tokyo, Japan) according to the manufacturer's instructions. Total RNA $(20 \mu \mathrm{g})$ was loaded on formaldehyde-agarose gel for electrophoresis and transferred to nylon membrane. DNA probes for mouse Fas and EF1- $\alpha$ were labeled with $\left[\alpha^{32} \mathrm{P}\right] \mathrm{dCTP}$ (specific activity $>3000 \mathrm{Ci} / \mathrm{mmol}, \mathrm{ICN}$ ) using an RTG-DNA labeling kit (Amersham Bioscience) with full-length mouse Fas $C D N A^{26}$ and full-length $E F 1-\alpha C D N A,{ }^{64}$ respectively, and purified using a NICK Column (Pharmacia Biotech) according to the manufacturer's instructions. The membrane was hybridized with probes using PerfectHyb Hybridization Solution (TOYOBO, Osaka, Japan) at $68^{\circ} \mathrm{C}$ overnight, and washed with $2 \times \mathrm{SSC} / 0.1 \%$ SDS for $5 \mathrm{~min}$ twice at $68^{\circ} \mathrm{C}$ and then $0.1 \times \mathrm{SSC} /$ $0.1 \%$ SDS for $30 \mathrm{~min}$ twice at $68^{\circ} \mathrm{C}$. The membrane was developed by placing it in contact with X-ray film.

\section{Flow cytometric analysis}

Testes dissected from 2- to 6-week-old wild-type C57B/6 and $W^{N} / W^{N}:$ Fas $^{+/+}$ mice were cut into small pieces with a razor blade and pipetted several times in PBS to isolate testicular cells, and the testicular single-cell suspension was collected through a nylon mesh. Aliquots of $1 \times 10^{6}$ cells were incubated for $1 \mathrm{~h}$ at $4^{\circ} \mathrm{C}$ with or without $1 \mu \mathrm{g}$ of FITC-conjugated antiFas mAb Jo-2 in flow cytometric buffer (PBS containing 5\% FCS and $0.04 \%$ sodium azide). In the case of double staining with both EE2 and Jo2 or triple staining with EE2, ACK2 and Jo-2, cells were initially incubated with an EE2 $\mathrm{mAb}$ for $1 \mathrm{~h}$ at $4^{\circ} \mathrm{C}$, then with a biotin-conjugate anti-rat $\kappa+\lambda$ light chain $\mathrm{mAb}$ for $30 \mathrm{~min}$. After blocking with rat IgG for $30 \mathrm{~min}$, cells were finally incubated with PE-conjugated avidin and FITC-conjugated Jo-2 or APC-conjugated avidin, PE-conjugated ACK2 and FITC-conjugated Jo-2 for $1 \mathrm{~h}$. NIH3T3 and its derivative NIH-K11 were stimulated with mouse recombinant SCF (Calbiochem) with or without wortmannin, LY294002, U0126 or PD98059 for $48 \mathrm{~h}$. Cells were then scraped with a rubber policeman and stained with Jo-2 as described above. All the samples, rinsed with flow cytometric buffer twice and fixed with PBS containing 3.5\% formaldehyde, were analyzed by flow cytometry on an EPICS Elite (Beckman Coulter).

\section{Establishment of stable transfectants}

Mouse c-kit cDNA subcloned into the vector pcDNA3 (Invitrogen) was provided by Drs. Ueda and Kanakura (Osaka University) and was introduced into NIH3T3 cells using Lipofectamin Plus reagent (Invitrogen). After selection with G418 and subsequent cloning, clones stably expressing Kit were established.

\section{Western blot analysis}

Total cell lysates of NIH3T3 cells and transfectants were separated by SDS-PAGE and transferred to PVDF membranes. Then, the membranes 
were immersed in Tris-buffered saline (pH 7.6) with $0.1 \%$ Tween 20 (TBST), 5\% skimmed milk and 2\% FCS at room temperature for $1 \mathrm{~h}$ and incubated with the primary antibodies at room temperature for $1 \mathrm{~h}$. The membranes were washed with TBS-T three times, and incubated with the secondary antibodies at room temperature for $1 \mathrm{~h}$. Specific signals were detected using the enhanced Western Lightning (PerkinElmer Life Science) detection system on X-ray film.

\section{Acknowledgements}

We thank Drs. Ueda and Kanakura, Dr. Kikkawa and Dr. Nishikawa for providing mouse c-kit cDNA, caAkt cDNA and anti-c-kit mAb ACK2, respectively. We thank Drs. Hisahiro Yoshida and Shin-ichi Nishikawa for their useful advice. This study was supported in part by Grants-in-Aid from the Ministry of Education, Culture, Sports, Science and Technology of the Japanese Government.

\section{References}

1. Qiu FH, Ray $P$, Brown $K$, Barker PE, Jhanwar $S$, Ruddle FH and Besmer $P$ (1988) Primary structure of C-kit: relationship with the CSF-1/PDGF receptor kinase family-oncogenic activation of $\mathrm{v}$-kit involves deletion of extracellular domain and $C$ terminus. EMBO J. 7: 1003-1011

2. Besmer P, Murphy JE, George PC, Qiu FH, Bergold PJ, Lederman L, Snyder Jr HW, Brodeur D, Zuckerman EE and Hardy WD (1986) A new acute transforming feline retrovirus and relationship of its oncogene $v$-kit with the protein kinase gene family. Nature 320: 415-421

3. Yarden Y, Kuang WJ, Yang-Feng T, Coussens L, Munemitsu S, Dull TJ, Chen E, Schlessinger J, Francke U and Ullrich A (1987) Human proto-oncogene c-kit: a new cell surface receptor tyrosine kinase for an unidentified ligand. EMBO J. 6: $3341-3351$

4. Chabot B, Stephenson DA, Chapman VM, Besmer P and Bernstein A (1988) The proto-oncogene $c$-kit encoding a transmembrane tyrosine kinase receptor maps to the mouse W locus. Nature 335: 88-89

5. Geissler EN, Ryan MA and Housman DE (1988) The dominant-white spotting (W) locus of the mouse encodes the c-kit proto-oncogene. Cell 55: 185-192

6. Copeland NG, Gilbert DJ, Cho BC, Donovan PJ, Jenkins NA, Cosman D, Anderson D, Lyman SD and Williams DE (1990) Mast cell growth factor maps near the steel locus on mouse chromosome 10 and is deleted in a number of steel alleles. Cell 63: 175-183

7. Huang E, Nocka K, Beier DR, Chu TY, Buck J, Lahm HW, Wellner D, Leder P and Besmer $P(1990)$ The hematopoietic growth factor KL is encoded by the $S$ locus and is the ligand of the c-kit receptor, the gene product of the $\mathrm{W}$ locus. Cell 63: 225-233

8. Zsebo KM, Williams DA, Geissler EN, Broudy VC, Martin FH, Atkins HL, Hsu RY, Birkett NC, Okino KH and Murdock DC (1990) Stem cell factor is encoded at the SI locus of the mouse and is the ligand for the c-kit tyrosine kinase receptor. Cell 63: 213-224

9. Russell ES (1979) Hereditary anemias of the mouse: a review for geneticists. Adv. Genet. 20: 357-459

10. Besmer P, Manova K, Duttlinger R, Huang EJ, Packer A, Gyssler C and Bachvarova RF (1993) The kit-ligand (steel factor) and its receptor c-kit/W: pleiotropic roles in gametogenesis and melanogenesis. Development, Suppl.: 125-137

11. Nocka K, Tan JC, Chiu E, Chu TY, Ray P, Traktman P and Besmer P (1990) Molecular bases of dominant negative and loss of function mutations at the murine c-kit/white spotting locus: W37, Wv, W41 and W. EMBO J. 9: 18051813

12. Reith AD, Rottapel R, Giddens E, Brady C, Forrester L and Bernstein A (1990) $W$ mutant mice with mild or severe developmental defects contain distinct poin mutations in the kinase domain of the c-kit receptor. Genes Dev. 4: 390-400

13. Manova K, Nocka K, Besmer $P$ and Bachvarova RF (1990) Gonadal expression of $\mathrm{c}-\mathrm{kit}$ encoded at the W locus of the mouse. Development 110: 1057-1069
14. Manova K, Huang EJ, Angeles M, De Leon V, Sanchez S, Pronovost SM, Besmer P and Bachvarova RF (1993) The expression pattern of the c-kit ligand in gonads of mice supports a role for the c-kit receptor in oocyte growth and in proliferation of spermatogonia. Dev. Biol. 157: 85-99

15. Rossi P, Dolci S, Albanesi C, Grimaldi P, Ricca R and Geremia R (1993) Follicle-stimulating hormone induction of steel factor (SLF) mRNA in mouse Sertoli cells and stimulation of DNA synthesis in spermatogonia by soluble SLF. Dev. Biol. 155: 68-74

16. Sandlow Jl, Feng HL and Sandra A (1997) Localization and expression of the ckit receptor protein in human and rodent testis and sperm. Urology 49: 494-500

17. Sorrentino V, Giorgi M, Geremia R, Besmer P and Rossi P (1991) Expression of the c-kit proto-oncogene in the murine male germ cells. Oncogene 6: 149151

18. Yoshinaga K, Nishikawa S, Ogawa M, Hayashi S, Kunisada T and Fujimoto $T$ (1991) Role of c-kit in mouse spermatogenesis: identification of spermatogonia as a specific site of c-kit expression and function. Development 113: 689-699

19. Schlessinger J (2000) Cell signaling by receptor tyrosine kinases. Cell 103: 211-225

20. Linnekin D (1999) Early signaling pathways activated by c-Kit in hematopoietic cells. Int. J. Biochem. Cell B 31: 1053-1074

21. Ashkenazi A and Dixit VM (1999) Apoptosis control by death and decoy receptors. Curr. Opin. Cell Biol. 11: 255-260

22. Yonehara S, Ishii A and Yonehara M (1989) A cell-killing monoclonal antibody (anti-Fas) to a cell surface antigen co-downregulated with the receptor of tumor necrosis factor. J. Exp. Med. 169: 1747-1756

23. Oehm A, Behrmann I, Falk W, Pawlita M, Maier G, Klas C, Li-Weber M, Richards S, Dhein J and Trauth BC (1992) Purification and molecular cloning of the APO-1 cell surface antigen, a member of the tumor necrosis factor/nerve growth factor receptor superfamily. Sequence identity with the Fas antigen. J. Biol. Chem. 267: 10709-10715

24. Suda T, Takahashi T, Golstein P and Nagata S (1993) Molecular cloning and expression of the Fas ligand, a novel member of the tumor necrosis factor family. Cell 75: 1169-1178

25. Rouvier E, Luciani MF and Golstein P (1993) Fas involvement in Ca(2+)independent T cell-mediated cytotoxicity. J. Exp. Med. 177: 195-200

26. Watanabe-Fukunaga $\mathrm{R}$, Brannan $\mathrm{Cl}$, Itoh $\mathrm{N}$, Yonehara $\mathrm{S}$, Copeland $\mathrm{NG}$, Jenkins NA and Nagata S (1992) The cDNA structure, expression, and chromosomal assignment of the mouse Fas antigen. J. Immunol. 148: 12741279

27. Yonehara S, Nishimura Y, Kishil S, Yonehara M, Takazawa K, Tamatani T and Ishii A (1994) Involvement of apoptosis antigen Fas in clonal deletion of human thymocytes. Int. Immunol. 6: 1849-1856

28. Nagata S and Golstein P (1995) The Fas death factor. Science 267: 14491456

29. Nishimura $Y$, Ishii A, Kobayashi $Y$, Yamasaki $Y$ and Yonehara $S$ (1995) Expression and function of mouse Fas antigen on immature and mature $T$ cells. J. Immunol. 154: 4395-4403

30. Suda T, Okazaki T, Naito Y, Yokota T, Arai N, Ozaki S, Nakao K and Nagata S (1995) Expression of the Fas ligand in cells of T cell lineage. J. Immunol. 154: 3806-3813

31. Leithauser F, Dhein J, Mechtersheimer G, Koretz K, Bruderlein S, Henne C, Schmidt A, Debatin KM, Krammer PH and Moller P (1993) Constitutive and induced expression of APO-1, a new member of the nerve growth factor/tumor necrosis factor receptor superfamily, in normal and neoplastic cells. Lab. Invest. 69: 415-429

32. Guo MW, Mori E, Xu JP and Mori T (1994) Identification of Fas antigen associated with apoptotic cell death in murine ovary. Biochem. Biophys. Res. Commun. 203: 1438-1446

33. Quirk SM, Cowan RG, Joshi SG and Henrikson KP (1995) Fas antigen-mediated apoptosis in human granulosa/luteal cells. Biol. Reprod. 52: $279-287$

34. Hakuno N, Koji T, Yano T, Kobayashi N, Tsutsumi O, Taketani Y and Nakane PK (1996) Fas/APO-1/CD95 system as a mediator of granulosa cell apoptosis in ovarian follicle atresia. Endocrinology 137: 1938-1948

35. Sakamaki K, Yoshida H, Nishimura Y, Nishikawa S, Manabe N and Yonehara S (1997) Involvement of Fas antigen in ovarian follicular atresia and luteolysis. Mol. Reprod. Dev. 47: 11-18

36. Kim JM, Boone DL, Auyeung A and Tsang BK (1998) Granulosa cell apoptosis induced at the penultimate stage of follicular development is associated with 
increased levels of Fas and Fas ligand in the rat ovary. Biol. Reprod. 58: 11701176

37. Roughton SA, Lareu RR, Bittles AH and Dharmarajan AM (1999) Fas and Fas ligand messenger ribonucleic acid and protein expression in the rat corpus luteum during apoptosis-mediated luteolysis. Biol. Reprod. 60: 797-804

38. Cataldo NA, Dumesic DA, Goldsmith PC and Jaffe RB (2000) Immunolocalization of Fas and Fas ligand in the ovaries of women with polycystic ovary syndrome: relationship to apoptosis. Hum. Reprod. 15: 18891897

39. Kondo H, Maruo T, Peng $X$ and Mochizuki M (1996) Immunological evidence for the expression of the Fas antigen in the infant and adult human ovary during follicular regression and atresia. J. Clin. Endocr. Metab. 81: 2702-2710

40. Adachi M, Suematsu S, Kondo T, Ogasawara J, Tanaka T, Yoshida N and Nagata $S$ (1995) Targeted mutation in the Fas gene causes hyperplasia in peripheral lymphoid organs and liver. Nat. Genet. 11: 294-300

41. Tres LL and Kierszenbaum AL (1999) Cell death patterns of the rat spermatogonial cell progeny induced by sertoli cell geometric changes and Fas (CD95) agonist. Dev. Dynam. 214: 361-371

42. Koji T (2001) Male germ cell death in mouse testes: possible involvement of Fas and Fas ligand. Med. Electron Microsc. 34: 213-222

43. Francavilla S, D'Abrizio P, Cordeschi G, Pelliccione F, Necozione S, Ulisse S, Properzi, G. and Francavilla, F. (2002) Fas expression correlates with human germ cell degeneration in meiotic and post-meiotic arrest of spermatogenesis. Mol. Hum. Reprod. 8: 213-220

44. Lee J, Richburg JH, Younkin SC and Boekelheide K (1997) The Fas system is a key regulator of germ cell apoptosis in the testis. Endocrinology 138: 20812088

45. Koji T, Hishikawa Y, Ando H, Nakanishi Y and Kobayashi N (2001) Expression of Fas and Fas ligand in normal and ischemia-reperfusion testes: involvement of the Fas system in the induction of germ cell apoptosis in the damaged mouse testis. Biol. Reprod. 64: 946-954

46. Ogi S, Tanji N, Yokoyama M, Takeuchi M and Terada N (1998) Involvement of Fas in the apoptosis of mouse germ cells induced by experimental cryptorchidism. Urol. Res. 26: 17-21

47. Yin Y, DeWolf WC and Morgentaler A (1998) Experimental cryptorchidism induces testicular germ cell apoptosis by p53-dependent and -independent pathways in mice. Biol. Reprod. 58: 492-496

48. Peli J, Schroter M, Rudaz C, Hahne M, Meyer C, Reichmann E and Tschopp J (1999) Oncogenic Ras inhibits Fas ligand-mediated apoptosis by downregulating the expression of Fas. EMBO J. 18: 1824-1831

49. Koshimizu U, Nishioka H, Watanabe D, Dohmae K and Nishimune $Y$ (1995) Characterization of a novel spermatogenic cell antigen specific for early stages of germ cells in mouse testis. Mol. Reprod. Dev. 40: 221-227

50. Kazama $\mathrm{H}$ and Yonehara $\mathrm{S}$ (2000) Oncogenic K-Ras and basic fibroblast growth factor prevent Fas-mediated apoptosis in fibroblasts through activation of mitogen-activated protein kinase. J Cell Biol. 148: 557-566
51. Kissel H, Timokhina I, Hardy MP, Rothschild G, Tajima Y, Soares V, Angeles M, Whitlow SR, Manova K and Besmer P (2000) Point mutation in kit receptor tyrosine kinase reveals essential roles for kit signaling in spermatogenesis and oogenesis without affecting other kit responses. EMBO J. 19: 1312-1326

52. Blume-Jensen P, Jiang G, Hyman R, Lee KF, O'Gorman S and Hunter T (2000) Kit/stem cell factor receptor-induced activation of phosphatidylinositol 3 '-kinase is essential for male fertility. Nat. Genet. 24:157-162

53. Jordan SA, Speed RM and Jackson IJ (1999) Deficiency of Trp53 rescues the male fertility defects of Kit(W-v) mice but has no effect on the survival of melanocytes and mast cells. Dev. Biol. 215: 78-90

54. Yin Y, Stahl BC, DeWolf WC and Morgentaler A (2002) P53 and Fas are sequential mechanisms of testicular germ cell apoptosis. J. Androl. 23:64-70

55. Yoshida H, Takakura N, Kataoka H, Kunisada T, Okamura H and Nishikawa SI (1997) Stepwise requirement of c-kit tyrosine kinase in mouse ovarian follicle development. Dev. Biol. 184: 122-137

56. Eppig JJ, Schultz RM, O'Brien M and Chesnel F (1994) Relationship between the developmental programs controlling nuclear and cytoplasmic maturation of mouse oocytes. Dev. Biol. 164: 1-9

57. Inazawa $Y$ and Yonehara S (1999) Fas-induced in vivo apoptosis in bone marrow: anti-Fas mAb-induced elimination and successive proliferation of Fasexpressing cells especially those of myeloid lineage. Cell Struct. Funct. 24: $151-159$

58. Chen WS, Xu PZ, Gottlob K, Chen ML, Sokol K, Shiyanova T, Roninson I, Weng W, Suzuki R, Tobe K, Kadowaki T and Hay N (2001) Growth retardation and increased apoptosis in mice with homozygous disruption of the Akt1 gene. Genes. Dev. 15: 2203-2208

59. Brunet A, Bonni A, Zigmond MJ, Lin MZ, Juo P, Hu LS, Anderson MJ, Arden KC, Blenis J and Greenberg ME (1999) Akt promotes cell survival by phosphorylating and inhibiting a Forkhead transcription factor. Cell 96: 857868

60. Panka DJ, Mano T, Suhara T, Walsh K and Mier JW (2001) Phosphatidylinositol 3-kinase/Akt activity regulates c-FLIP expression in tumor cells. J. Biol. Chem. 276: 6893-6896

61. Tanaka H, Pereira LA, Nozaki M, Tsuchida J, Sawada K, Mori H and Nishimune Y (1997) A germ cell-specific nuclear antigen recognized by a monoclonal antibody raised against mouse testicular germ cells. Int. J. Androl. 20: 361-366

62. Nishikawa S, Kusakabe M, Yoshinaga K, Ogawa M, Hayashi S, Kunisada T, Era T and Sakakura T (1991) In utero manipulation of coat color formation by a monoclonal anti-c-kit antibody: two distinct waves of c-kit-dependency during melanocyte development. EMBO J. 10: 2111-2118

63. Senju S, Negishi I, Motoyama N, Wang F, Nakayama KI, Nakayama K, Lucas PJ, Hatakeyama S, Zhang Q, Yonehara S and Loh DY (1996) Functional significance of the Fas molecule in naive lymphocytes. Int. Immunol. 8: 423431

64. Lu XA and Werner D (1989) The complete cDNA sequence of mouse elongation factor 1 alpha (EF 1 alpha) mRNA. Nucleic Acids Res. 17: 442 